\title{
HISTÓRIA E FENOMENOLOGIA EXISTENCIAL DO CORPO: UMA CONTRIBUIÇÃO TEÓRICA À HUMANIZAÇÃO DAS CIÊNCIAŞ DA SAÚDE
}

\author{
HISTORIA Y FENOMENOLOGÍA EXISTENCIAL DEL CUERPO: \\ UNA CONTRIBUCIÓN TEÓRICA A LA HUMANIZACIÓN DE \\ LAS CIENCIAS DE LA SALUD
}

HISTORY AND EXISTENTIAL PHENOMENOLOGY

OF THE BODY: A THEORETICAL CONTRIBUTION

TO THE HUMANIZATION OF HEALTH SCIENCES

\section{CARLOS HENRIQUE ARMANI*}

\section{RESUMO}

O objetivo desse artigo é refletir sobre a contribuição que a fenomenologia existencial pode proporcionar para a compreensão da experiência subjetiva da corporalidade humana no contexto da história do corpo na modernidade. Entendo que a problematização do corpo humano como subjetividade pode beneficiar o processo de humanização das ciências da saúde.

Palavras-chave: História do corpo, corporalidade, fenomenologia existencial, humanização da saúde.

\section{RESUMEN}

El objetivo de este artículo es reflexionar sobre la contribución que la fenomenología existencial puede proporcionar a la comprensión de la experiencia subjetiva de la corporalidad humana en el contexto de la historia del cuerpo en la modernidad. Entendemos que una problematización del cuerpo humano como subjetividad puede beneficiar el proceso de humanización de las ciencias de la salud.

Palabras clave: Historia del cuerpo, corporalidad, fenomenología existencial, humanización de la salud.

* Doutor em História, Departamento de História da Universidade Federal de Santa Maria, Rio Grande do Sul, Brasil. E-mail: carlos.armani@gmail.com 


\section{ABSTRACT}

This paper aims to reflect on the contribution that existential phenomenology can provide to the understanding of the subjective experience of human corporality in the context of modern history of the body. We understand that the problematization of the human body as subjectivity can benefit the humanization process of the health sciences.

Keywords: History of the body, corporeality, existential phenomenology, health humanization.

Recibido: 14.06.16. Aceptado: 20.09.16.

\section{A) INTRODUÇÃO}

RETENDO APRESENTAR, neste artigo, algumas ideias sobre a experiência subjetiva do corpo, fundamentadas no método fenomenológico _ existencial, de modo que seja possível relativizar a lógica binária e reducionista de produção e reprodução da teoria e da prática do conhecimento científico moderno aplicada às ciências da saúde, o que implica a relativização de uma longa história que transformou o corpo humano, na saúde, em objeto de uma ordem de saber e de prática que, se por um lado, trouxe progresso inquestionável para parcela da humanidade, por outro, paradoxalmente, corroeu o que havia de humano nessa relação, especialmente por reduzir o mundo a uma esfera de explicação calcada exclusivamente na natureza. Para tal empreendimento, dividi o texto em duas partes, nas quais abordarei: a) aspectos da construção do pensamento científico moderno, especialmente seus predicados de matematização/objetivação do real e de fragmentação, como também a sua relação com a história do corpo humano; b) a perspectiva teórico-metodológica da fenomenologia existencial que se desenvolveu na esteira da crítica à objetivação do ser humano operada no século XX. Espero que a reflexão ora apresentada possa servir para o processo de humanização da saúde, tanto em seu nível epistemológico, relativo à produção do conhecimento científico da saúde, como também em sua racionalidade mais prática, no âmbito das diversas instituições voltadas para o atendimento da saúde.

A motivação para a realização dessa tarefa está relacionada com a tomada de consciência de que o fazer ciência evoca realidades complexas em sua atividade que não podem ser decompostas em termos analíticos nem universalizáveis em padrões estatísticos, uma vez que a ciência, como atividade humana, é cultural e intersubjetiva por excelência. E quando o assunto é saúde, as tendências de interrelação entre o universo subjetivo e a produção 
do saber autorizado para intervir no corpo tornam-se ainda mais efetivas. O problema é que tal estreitamento, às vezes, causa embaraços com a falta de ponderabilidade que tais cruzamentos eventualmente oferecem.

No decorrer da história das ciências que futuramente viriam a ser identificadas como ciências da saúde, houve um processo paulatino de redução de seu objeto -o corpo humano- a uma instância de racionalidade calculista como razão última de seu sentido, cujo correspondente epistemológico foi a elaboração de uma visão de mundo cindida entre sujeito e objeto do conhecimento, traduzindo-se em uma compreensão do corpo humano extensiva à natureza. Qualquer conciliação entre ambos implicaria a perda de credibilidade da razão normativa, responsável pela determinação da verdade a ser consagrada pela ciência. A extirpação da subjetividade do devir-saúde é diretamente proporcional à busca de sua cientificidade e de sua calculabilidade epistemológica, econômica e política. E aqui, inscreve-se o dilema: ainda que as ciências da saúde sejam portadoras de um saber que as autoriza a manipular o corpo humano como objeto, sem o referencial subjetivo que permeia a definição de humanidade -e no qual tais ciências se incluem como ciências do humano e não do ser vivo em geral- elas sequer fariam sentido em existir.

Nesse contexto mais amplo é que se insere a fenomenologia existencial do corpo como uma modalidade de entendimento do ser humano que não o reduz a seus componentes naturais, relativizando-os em uma dimensão intersubjetiva e existencial. Bem sabemos que uma parte significativa da literatura acerca da humanização em saúde trata de aspectos que distinguem o ser humano dos demais seres vivos a partir de uma particularidade: a capacidade de linguagem e construção de significados para a saúde, para a doença, para a vida e para a morte.

Evidentemente, falar sobre os aspectos simbólicos relativos ao espírito seria um pouco mais acessível do que falar sobre a valorização do corpo como fator de humanização, sobretudo porque, como diz Sartre, "nosso acesso ao corpo se dá muito mais como uma propriedade do que como ser” (1997, p. 386). Minha intenção, contudo, é falar sobre os valores humanos na saúde, tendo em vista não aspectos que tradicionalmente nos remetem a ideias de alma, de espírito e de valores transcendentais em relação ao efêmero, ao corpóreo e ao sensorial, mas, pelo contrário, centrar minha análise na esfera humana do sensorial e do corpóreo, pois é neles que a saúde existe, também -se não exclusivamente- como ciência humana. Por mais naturalizado que seja o corpo nos processos explicativos causais das ciências da saúde, é o corpo humano que está sendo explanado, e não o cor- 


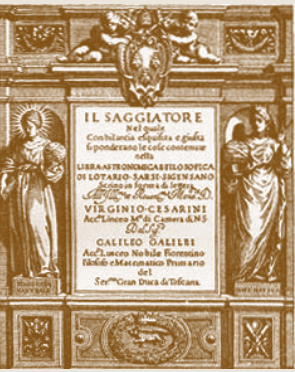

po de uma planária, de uma mosca ou de um cão. Nesse sentido, convém problematizar a humanização da saúde em uma perspectiva centrada na história intelectual do corpo humano na modernidade, na qual podemos vislumbrar sua conversão em objeto de um saber e, simultaneamente, sua capacidade de manter a especificidade humana em que a existência se dá como condição para o humano habitar o mundo no qual vive e dotá-lo de sentido. Feita essa constatação, o que o método fenomenológico existencial pode oferecer como modo de compreensão do corpo no contexto da saúde, sem resvalar para a humanização instrumental? Antes de responder a esta questão, importa apresentar os termos do debate, o que nos remete para alguns aspectos históricos da constituição da ciência moderna do corpo humano e sua fabricação como objeto.

\section{B) A CONSTRUÇÃO DA CIÊNCIA MODERNA, A DICOTOMIZAÇÃO SUJEITO-OBJETO E A SAÚDE NO CONTEXTO DA HISTÓRIA DO CORPO}

Ao pensarmos a história da modernidade, desse grande projeto filosófico inaugurado com a ciência e a filosofia a partir dos séculos XVI e XVII, tendemos a pensar que a razão mecanicista e quantitativa paulatinamente se separou da razão sensível, qualitativa e valorativa. De fato. Tal dicotomização faz parte de um longo processo em que um conjunto de ideias e de ações sobre o mundo tornou-se hegemônico, dando azo ao que convencionalmente denominamos de razão instrumental, de um tipo de saber e prática que tendeu a uniformizar, mecanizar, reduzir e decompor a realidade e convertê-la ao domínio do calculável e do despoetizado.

Quando Galileu Galilei escreveu $O$ ensaiador, em 1623, as opiniões acerca da natureza haviam mudado muito, se comparadas com a visão encantada e mágica que os renascentistas haviam criado e recriado em sua conflituosa relação com o passado medieval e com o passado da Antiguidade Clássica. Galileu afirmou que requintes poéticos não traziam fruto para a ciência e que a natureza não se deleitava com poesias (Galileu Galilei, 1999, p. 49). No mesmo livro, o filósofo e matemático escreveu:

A filosofia encontra-se escrita neste grande livro que continuamente se abre perante nossos olhos, que não se pode compreender antes de entender a língua e conhecer os caracteres com os quais está escrito. Ele está escrito em língua matemática, os caracteres são triângulos, circunferências e outras figuras geométricas, sem cujos meios é impossí- 
vel entender humanamente as palavras; sem eles nós vagamos perdidos dentro de um obscuro labirinto (Galileu Galilei, 1999, p. 46).

Galileu foi a expressão de um clima de opiniões e de ideias que vigorava na cultura intelectual europeia do século XVII. Além da matematização da natureza, sua decomposição em termos analíticos se tornou uma das pedras de toque do período. A sociedade europeia estava diante de uma nova ideia sobre o ser do mundo, em que a autoridade dos antigos cada vez mais passava a ser questionada, em prol de uma explicação naturalista dos fenômenos. A natureza havia mudado e, com ela, inserida nela, a noção de corpo humano. Foi na modernidade, a partir do século XVII, que o corpo humano passou a ser um objeto ordenado, uno e mecânico -e não sujeito- da ciência. Com o avanço da geometrização do saber, do saber claro e distinto que ordenava, separava e nada omitia, o corpo humano se tornou, como os demais corpos da natureza, uma extensão.

Seria errôneo pensar que Galileu tivesse em mente a saúde quando escreveu $O$ ensaiador. Não obstante, disciplinas básicas que viriam a fazer parte do currículo de quase todas as ciências da saúde, como anatomia, fisiologia e patologia, paulatinamente se apropriaram de um saber sobre o corpo, que tinha nas analogias com a hidráulica e com a mecânica seu maior fundamento. Se não seria possível usar sempre os caracteres geométricos para a construção do saber sobre a saúde, o certo é que a matemática, a razão reducionista e a teoria corpuscular-cinética forneceram as bases de fundamentação para a anatomia e para a fisiologia do corpo humano, do mesmo modo que a geometria havia feito em relação à explicação do cosmos: em ambos os casos, não se pretendia vagar perdido pelo imponderável labirinto da escuridão. Do macrocosmo do universo ao microcosmo do corpo e suas partes, a linguagem que os unificava e os descrevia era a matemática.

A descoberta da circulação do sangue, por William Harvey, e a publicação de sua obra mestra, De Motus Cordis, em 1628, contribuiu para essa identificação do corpo humano com a mecânica. A exemplo dos modernos do seu tempo, Harvey propunha uma teoria que contrariava a tradição médica antiga, em especial galênica, ao sustentar que o sangue seguia uma direção na qual ele retornava sobre si mesmo, diferente da descrição fisiológica proposta por Galeno no século II da era cristã (Harvey, 2009, p. 199). Em que pese Harvey falar sobre espíritos vitais que distribuíam propriedades sobre o corpo -linguagem comum a Galeno- não há dúvida de que ele falava de um modo alegórico, pois a circulação do sangue não dependia de nenhum vitalismo; pelo contrário, em seu pensamento, era função das

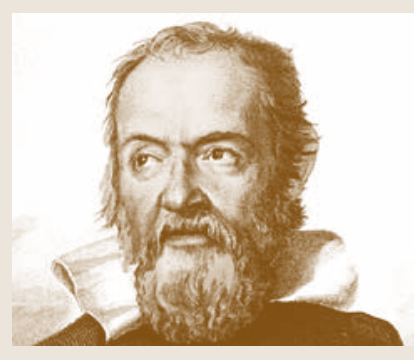

G. Galilei
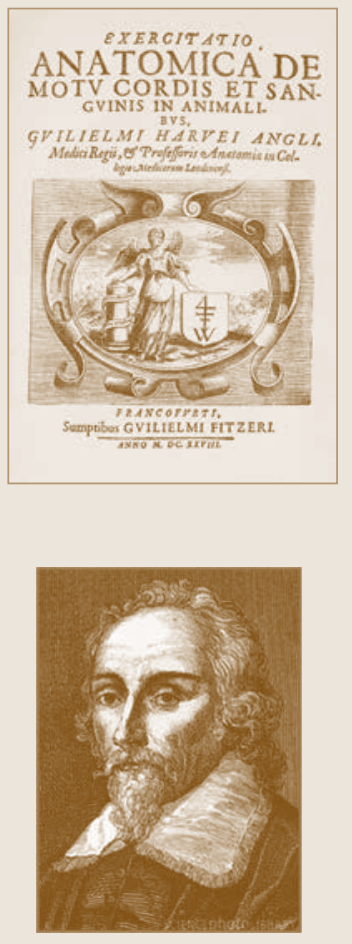

W. Harvey 


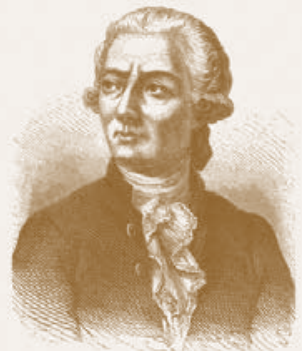

A. Lavoisier
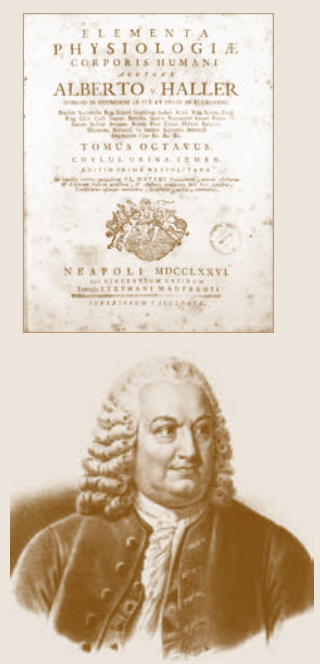

A. von Haller artérias distribuir o sangue do coração a todo o corpo. Para ele, "um sangue carregado de espíritos nada mais é que sangue" (Harvey, 2009, p. 206). Do mesmo modo que em Galileu, a natureza do corpo humano, em Harvey, não se deleitava com poesias. Em Harvey podemos vislumbrar a tradução da teoria galileana acerca do universo para o corpo humano. Não caberia ao anatomista nem ao fisiologista buscar aspectos transcendentais e mágicos no corpo e no seu microcosmo. Indubitavelmente, tal visão de mundo contribuiu para o esvaziamento da teologia na definição dos rumos da atividade científica, mas serviu, também, para dessubjetivar o corpo humano -ou sequer permitir a sua elaboração.

A relação da biologia aplicada ao ser humano com a química e com a física não parou no século XVII; pelo contrário: o século XVIII radicalizou essa relação. Foi no Setecentos que Lavoisier desenvolveu a teoria da combustão e, com ela, explicou a passagem de gases para os pulmões. A respiração era o análogo no corpo vivo, à combustão no mundo externo: ambos necessitavam de oxigênio, ambos produziam dióxido de carbono e água (Porter, 2004, p. 92). Herman Boerhaave falava de sistemas físicos que operavam em todo o corpo e que compreendiam um todo equilibrado, integrado, no qual as pressões e fluxos líquidos eram nivelados, encontrando seu próprio equilíbrio. A saúde era explicada pelo movimento dos líquidos no sistema vascular; a doença era explicada em termos de sua obstrução ou estagnação. Em seu Elementos de fisiologia do corpo humano, publicado entre 1757 e 1766, Albrecht Von Haller demonstrou a hipótese de que a irritabilidade era uma propriedade inerente às fibras musculares, enquanto a sensibilidade era um atributo exclusivo das fibras nervosas (Russo, 2006, p. 103). Baseadas em procedimentos experimentais realizados em animais $\mathrm{e}$ em seres humanos, as teorias de Haller diferenciavam as estruturas orgânicas de acordo com sua composição em fibras, atribuindo a elas sensibilidades intrínsecas independentes de qualquer alma transcendental. Em Haller, o movimento do corpo humano relacionado à alma seria necessariamente um movimento consciente. Qualquer movimento involuntário ou movimento de órgãos isolados que não fossem conscientes seria resultado da irritabilidade (Russo, 2006, pp. 103-104).

O materialismo não se esgotou em Haller. A teoria mais radical do materialismo cientificista do século XVIII foi a de Luigi Galvani, ao afirmar que a eletricidade estava envolvida e conectada à força vital. Alessandro Volta, em seus estudos sobre a eletricidade humana, deu continuidade a tais estudos, nos quais demonstrou que seria possível fazer um músculo contrair-se por estímulo elétrico. George Adams, em 1799, afirmou que a teoria da 
eletricidade era ainda vista com certa desconfiança em seu meio, mas que seria fundamental para o avanço da humanidade reconhecê-la como uma ciência (Adams, 1799, pp. 484-485). La Méttrie, não somente em sua obra mais conhecida, O homem-máquina, como também em trabalhos como o Tratado da alma, condensou a visão de mundo que pairava no horizonte do pensamento científico: o homem não passaria de uma máquina cujas principais decisões relativas à vida eram processos fisiológicos mecanicamente constituídos e originados da matéria. A alma, o pensamento metafísico, o pensamento ético, enfim, tudo era apenas o resultado de processos orgânicos e temporalmente finitos como tais (La Méttrie, 1796, p. 259).

A ciência biomédica se encaminhava para a base experimental que a consolidaria no século XIX. As ideias contidas na obra Introdução ao estudo da medicina experimental, de Claude Bernard, publicada em 1865, eram sintomáticas desse período que via, na experimentação científica, a base de toda a ciência biomédica. A medicina experimental deveria se diferenciar da medicina especulativa e empírica dos séculos precedentes. Para tanto, ela deveria se sustentar em um tripé: a fisiologia, a patologia e a terapêutica. A fisiologia era o conhecimento das causas dos fenômenos da vida em estado normal, a patologia o conhecimento das doenças e das causas que as determinavam e a terapêutica o conhecimento que, por um lado, conduzia para a prevenção das condições mórbidas e, por outro, ao combate dos seus efeitos por meio de agentes medicamentosos para o fim de curar as doenças (Bernard, 2008, pp. 31-32). A medicina científica funcionava em termos comparativos. Se havia um domínio de normalidade da vida, cognoscível por meio da fisiologia, qualquer desvio do meio interior -ou homeostase, termo que seria cunhado pelo fisiologista Walter Cannon no século XXque regulava esse estado natural seria alvo de ação médica, de modo que fosse feita sua reparação em termos terapêuticos. Em que pese a visão de Bernard ser, em certo sentido, aberta para contingências, a experimentação biomédica seguiu o modelo mecanicista já consolidado, juntando a ele a lógica de explicação reducionista, em voga com o crescimento sistemático das especializações a partir da segunda metade do século XIX. A vida somente seria entendida, nessas circunstâncias, como uma determinação biológica. Como disse Bichat (1994, p. 58) em livro clássico de 1822, a vida era nada mais do que o conjunto das funções que resistiam à morte. Os princípios de ação e de reação do corpo para manter a vida não eram mais do que processos físico-químicos mecânicos de seu funcionamento e de sua regulação. Mesmo realidades concebidas como metafísicas -a vida e a morte- foram naturalizadas e convertidas em objeto de saber da ciência
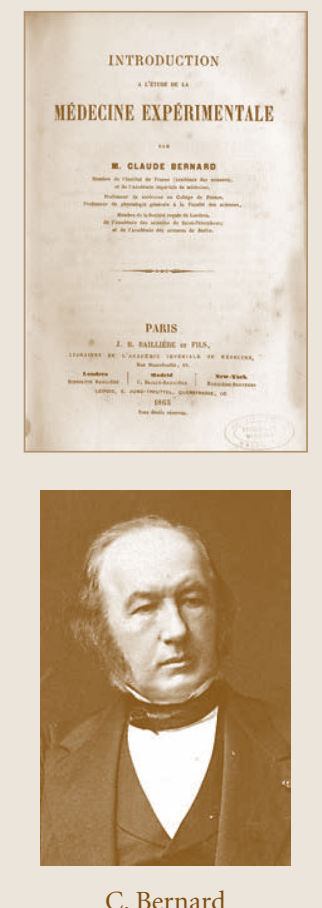

C. Bernard 
natural. Tratava-se, sem dúvida, de uma cosmovisão que transcendia a obra desses autores e que paulatinamente se consolidava como a visão da ciência na saúde. Prevaleceu a lógica de uma ciência biomédica experimental que reduziu sua realidade à experimentação estatisticamente comprovada e ao mínimo denominador comum das doenças, que poderia variar conforme a especialidade com a qual se estava lidando. Havia um estado normal e a patologia seria o desvio dessa normalidade. Agir terapeuticamente era fazer o estado fisiológico voltar à sua normalidade, por meio de técnicas de reparo sobre o corpo-objeto.

Uma outra face da conversão do corpo-sujeito em corpo-objeto na saúde, em especial na sua disciplina mais tradicional -a medicina- proveio daquilo que Foucault denominou de biopolítica (Foucault, 1988, p. 80), ou seja, da socialização, no capitalismo, do corpo enquanto força de produção e de trabalho. Trata-se de um modo de controle da sociedade sobre os indivíduos diretamente sobre o seu corpo, uma espécie de investimento político do capitalismo no somático, no biológico. Seria ingênuo pensar que o desenvolvimento das ciências da saúde ocorreu de modo separado da biopolítica, como se a politização do somático fosse um investimento do capitalismo, independente da ciência. Não o era. O governo da vida, realizado em instituições como a prisão, a escola e o hospital, passava pelo conhecimento científico do corpo humano. Administrar vidas, medi-las pela estatística, prolongar sua duração pela higiene, investigar taxas de natalidade e de mortalidade eram algumas das características da biopolítica (Fassin, 2006, p. 324).

A economia e a administração do corpo pela saúde passou por, pelo menos, dois processos: primeiro, o corpo como máquina, nos quais promovia-se seu adestramento, a ampliação de suas aptidões, a extorsão de suas forças, o crescimento paralelo de sua utilidade e de sua docilidade, a sua integração em sistemas de controle eficazes e econômicos; o segundo, a biopolítica da população, a centralização da medicina no corpo-espécie, no corpo transpassado pela mecânica do ser vivo e como suporte dos processos biológicos: proliferação, nascimentos, mortalidade, nível de saúde, longevidade, entre outros fatores (Foucault, 1988, pp. 150-152). Não se tratava, portanto, de pensar a biopolítica somente como uma realidade da saúde coletiva. O corpo-espécie era, mesmo que coletivamente falando, o corpo da anatomia, da fisiologia e da patologia.

A realidade biopolítica e a cientifização da saúde foram duas dimensões dinâmicas de um processo de subsunção do sujeito pela racionalidade normativa e instrumental que se operava tanto nos laboratórios quanto 
no Estado. A quantificação da ciência por meio da geometria e da estatística era apenas a correspondente, nas academias e nas universidades, da matematização da administração e da gestão do Estado moderno. Poderia objetar-se que a preocupação com taxas de natalidade e de mortalidade por parte das ciências biomédicas não estaria relacionada a uma objetivação do ser humano e, menos ainda nos casos em que tais ciências investiram na ideia do bem-estar subjetivo. Não obstante, a invenção de si e o investimento correspondente no valor da vida como valor político único e último é o cerne da biopolítica moderna, implicando uma soberania sobre os corpos não somente no domínio público, como também -e sobretudo- no âmbito privado (Agamben, 2002, p. 127). Práticas alimentares racionalizadas, realização de exercícios físicos, modos corretos de caminhar e de manter a postura, como ter ou não ter filhos, rotinas cotidianas regradas em todos os níveis - da cozinha ao banheiro- são sintomáticas de uma era em que a intervenção das ciências da saúde no domínio privado é o epicentro da vida natural do homem, tornando quase que indistintas as fronteiras entre o moral e o físico. Poderíamos dizer que, com a biopolítica, o natural é moral e o biológico é político. Hábitos cotidianos, realizados na intimidade de si, são partes de uma realidade em que as regras do "privado" são prescritas pelo especialista, pelo sujeito cuja competência técnica na regulação do corpo é inquestionável. Por mais que se fale em subjetivação nesse processo, ela não passa de uma submissão rigorosa a um modelo de "vida que merece ser vivida", em contraposição à "vida indigna de ser vivida", uma demarcação do que está dentro da vida e do que está fora dela (Agamben, 2002, p. 138).

As disciplinas que compõem o quadro básico das ciências da saúde passam por essa dinâmica de explicação do humano no seu somático. A anatomia, a fisiologia e a patologia são apenas alguns exemplos de um rol de saberes que centram seu poder de intervenção no mecânico, no objeto, na racionalidade fragmentada de corpos biologicamente universalizáveis e, portanto, extensivos. É com base nesse fundamento que as ciências da saúde legitimam-se como saberes científicos. E é com eles, outrossim, que sua virtude humana acaba se perdendo no labirinto do fragmento e da extensão. Seu ensino, basicamente, se inscreve em uma lógica na qual o desvio do padrão classificatório, estatístico, reducionista e molecular implica imersão na incerteza e, portanto, no não-científico, ou melhor, em certa visão da ciência que não aceita a incerteza como uma de suas condições de possibilidade. Não obstante, é neste imponderável que é possível encontrar um caminho, entre outros, de humanização das ciências da saúde por meio 
da qual o corpo seja tomado, no mínino, na tensão constitutiva de seu ser: parte natureza, parte cultura.

\section{C) A FENOMENOLOGIA EXISTENCIAL DO CORPO COMO INSTÂNCIA DE HUMANIZAÇÃO DA SAÚDE}

Diante do exposto, seria válido afirmar que o paradigma moderno não tem mais validade, que os progressos científicos atingidos pelas ciências da saúde, às custas do esforço de conversão da realidade em natureza, devem ser abandonados? Que a decomposição analítica e o reducionismo são métodos que não explicam a ciência e nem servem como seus fundamentos? Evidentemente, a resposta é não. Quando falo de corpo-objeto, não quero dizer que não seja possível dar esse tratamento ao corpo quando analisado em anatomia, em fisiologia, em patologia, em citologia ou em qualquer outra das disciplinas básicas da tecnologia do corpo. O problema é converter o corpo humano da anatomia e da fisiologia no corpo humano como tal. Afirmar que o corpo humano é anatomia e é fisiologia não é a mesma coisa que dizer que o corpo humano seja exclusivamente anatomia e fisiologia. Não se trata de operar, aqui, por dicotomias do tipo isto ou aquilo. Se, por um lado, a ciência produziu a desumanização do humano, por outro, paradoxalmente, ela trouxe consideráveis -mas parciais-avanços para os homens nas mais diversas áreas de conhecimento e da vida em sociedade. Não obstante, tais avanços são insuficientes para apreender o humano na saúde. Nesse sentido, uma contribuição que pode ser apresentada no âmbito metodológico da filosofia e das ciências humanas acerca desses operadores do corpo e do espírito que formam as ciências da saúde é a fenomenologia existencial.

Nós somente somos o que somos porque somos corporalidade. Não corporalidade como fenômeno estanque e solto no espaço, mas um corpo-existência lançado no mundo. O mundo do cotidiano, do trabalho, do afeto, da violência, do lazer, enfim, o mundo da existência, do lançar-se-parafora-de-si. O que resta do eu sem corpo? Seguindo certa fenomenologia da percepção, é possível afirmar que somos corpo. Se apresento um problema no fígado, ou nos rins, ou no coração, sou eu enquanto fígado, rins e coração que tenho um problema. Minhas mãos são "eu-que-pego" meus pés são "eu-que-ando", meus olhos são "eu-que-vejo" (Luijpen, 1973, p. 55). Meu corpo não é um apêndice de mim. Não posso existir sem ele. Posso produzir valores, cultura, religião, economia, posso falar, escrever, me submeter 
a um tratamento de saúde e deitar-me em um leito de hospital, mas não posso fazer tudo isso sem um corpo. Como afirma Merleau-Ponty (1969, p. 139), "nada que seja humano é completamente incorporal". O humano do corpo humano não é expresso pela fisiologia e nem pela anatomia. Nessas disciplinas, o corpo humano é parte de um conjunto de corpos físicos que são tomados como objeto, entre outros, das ciências biomédicas. Nelas, especialmente na anatomia, o corpo morto é um corpo despersonalizado e abstraído do que possa efetivamente significar a vida humana. Não temos, nessas condições, o corpo-pessoa (Russo, 2006, p. 184). O corpo humano é humano porque é "meu", "teu", "dela", "dele", quer dizer, o corpo de um sujeito (Luijpen, 1973, p. 55). O que se constitui como eu e subjetividade não é o simples resultado de uma consciência de si mesmo solta no universo do pensamento, mas uma subjetividade que depende de um corpo que cria linguagem, manipula símbolos e valores, enfim, que fabrica cultura. Não há humanidade que escape do estar lançado no mundo como corporalidade. Se mantivermos, na compreensão das ciências da saúde, a concepção do corpo como uma coisa entre outras, um apêndice pertencente ao grande grupo de corpos da ciência, semelhante ao corpo bruto -como pretendia Claude Bernard-, toda essa dimensão fenomenológico-existencial permanecerá ininteligível.

Resumindo: o corpo é sujeito. Quer dizer: se a tradição científica moderna nos orientou para pensarmos a realidade exterior ao sujeito como algo que pode ser objeto de estudo do homem e, portanto, que se conforme em seu objeto de observação, de medição e de explicação, a fenomenologia existencial pode questionar a imobilidade do objeto e deslocá-lo para a própria historicidade que o constitui, jogando com as fronteiras, muitas vezes tênues, que existem entre o sujeito e o objeto do conhecimento. Se o corpo é compreendido somente como uma extensão, com suas determinações anatômicas e fisiológicas pré-estabelecidas, como um número qualquer no quadro geral da impessoalidade estatística, ele será reduzido a certo ser-objeto cuja implicação ética é negada antes mesmo de qualquer possibilidade de instauração de uma relação efetivamente intersubjetiva -o outro sempre convertido ao mesmo.

Mas onde, efetivamente, estabelecemos essa relação entre sujeitos e sujeitos? No mundo histórico, que implica a economia, a sociedade, a cultura, a ciência como um conjunto articulado e nunca isolado de um todo que podemos aqui denominar de mundo de sentidos e de significados que são atribuídos e atribuíveis às mais diversas situações existenciais pelas quais passamos -o sentido que atribuímos à vida, à morte, à alimentação, ao con- 
vívio, ao poder, à saúde, à doença, à saúde na doença etc. Como sugere Ayres (2007, p. 51), do ponto de vista conceitual e prático da saúde, temos como tarefa fundamental "liberar nossa capacidade de escolha dos 'quê fazer?' em saúde da sua colonização pelos juízos fechados e predeterminados da conceitualidade instrumental da biomedicina". Com a fenomenologia existencial, nos é permitido que ampliemos o olhar do significado existencial da saúde, que levemos em consideração a relação sujeito-sujeito que subjaz e fundamenta toda a prática de convívio -do viver em comum- em sociedade, uma vez que a saúde, como qualquer realidade humana, é realizada por seres humanos, entre seres humanos, para seres humanos, em sociedade. Podemos afirmar que toda a epistemologia é também uma ética, na qual o corpo é sujeito do saber e do existir.

\section{D) CONSIDERAÇÕES FINAIS}

O sentido ético que mobilizou os esforços para a construção deste artigo não é mais do que uma perspectiva de mundo com intenção de contribuir para o processo corrente de humanização das ciências da saúde, tanto epistemológica quanto eticamente, e contribuir, teoricamente, para tornar a sua prática no hospital, na clínica, nas emergências, nos pronto-socorros, mais saudáveis de um ponto de vista existencial. Contudo, é necessário que tenhamos o cuidado em não converter a vontade de potência -com toda a afirmatividade que ela comporta- em vontade de poder. Transformar a humanização em um instrumento, em um meio de atingir um fim, especialmente a finalidade do atendimento humano diferenciado para fins de aumento das taxas de lucro da indústria hospitalar -cujos programas de qualidade total são uma das faces dessa lógica- nada mais é do que o embelezamento, por via desses conceitos, de um verdadeiro caos de disputas pelo mercado do corpo-que-merece-ser-tratado e que pode pagar por tais serviços. Podemos inclusive pensar que o poder da vida, no sentido foucaultiano do termo, casa muito bem com a ideia de humanização. Não seria a humanização mais um modo, entre outros, de promover o poder soberano sobre a vida, o poder de causar a vida e não a morte, de exercer sua gestão, sua majoração e sua multiplicação sobre a vida? (Foucault, 1988, p. 149). Creio que seria ingênuo deixar tal realidade de lado, especialmente no contexto de industrialização e mercantilização da saúde, em que vale tudo para ganhar um novo corpo-extensão-cliente. Ao longo desse texto, em nenhum momento tive como objetivo avalizar essa postura de uma humanização 
instrumental, tão cara à lógica do capital. Isso não impede, contudo, que consideremos, seriamente, a contribuição da fenomenologia existencial do corpo como razão sensível, relativizando o ser-objeto corpo que constitui epistemologicamente as ciências da saúde. Além disso, a fenomenologia existencial deve, também, contribuir para instaurar a compreensão como atitude fundamental do ser e do devir-saúde. Compreensão quer dizer, aqui, imergir no ser-aí que somos e estamos, na razão perspectiva que nos constitui, nas circunstâncias que nos determinam e que determinamos, $o$ que vai além das fronteiras impostas pelo patrimônio conceitual da ciência moderna, uma vez que a compreensão pertence à experiência humana do mundo e atravessa todas as referências humanas ao mundo (Gadamer, 2004, p. 23). Não há dúvida de que tais perspectivas metodológicas -se é que assim podemos classificá-las- tendem a inundar o conhecimento das ciências da saúde de imponderáveis. Mas a questão é que os imponderáveis humanos nunca deixaram de estar presentes nesse grande fenômeno que denominamos saúde e sem o qual nenhuma ciência da saúde existe. A humanização é uma relação constante, permanente, entre sujeitos e sujeitos, ainda que muitos deles estejam submetidos à perversão do poder.

Não há dúvida de que somos um centauro ontológico, como dizia Ortega y Gasset (1963, p. 38): parte natureza e parte cultura. Ainda que de modo precário, a fenomenologia existencial pode reduzir esse imenso abismo existente entre modos de subjetivação e de objetivação do corpo, alargando seu entendimento em um quadro conceitual fenomenológico-existencial. Para finalizar com uma provocação, penso que tal contribuição pode fazer com que percamos um pouco da cientificidade tradicional que as ciências da saúde reivindicam para si, mas por outro, que ganhemos em realidade.

\section{REFERENCIAS}

Adams, G. (1799). An essay on electricity, explaining the principles of that useful science. London: J. Dillon.

Agamben, G. (2002). Homo sacer: o poder soberano e a vida nua. Belo Horizonte: Ed. da UFMG.

Ayres, J. R. (2007). Uma concepção hermenêutica de saúde. Physis: Revista de Saúde Coletiva, Rio de Janeiro, 17(1): 43-62.

Bernard, C. (2008). Introduction à l'étude de la medicine expérimentale. Paris: Flammarion.

Bichat, F. X. (1994). Recherches physiologiques sur la vie et la mort. Paris: Flammarion. 
Fassin, D. (2006). Biopolítica. In: Russo, M., Caponi, S. (orgs.). Estudos de filosofia e história das ciências biomédicas. São Paulo: Discurso Editorial.

Foucault, M. (1988). História da sexualidade - A vontade de saber. Rio de Janeiro: Graal.

Gadamer, H.-G. (2004). Verdad y método. Salamanca: Sigueme.

Galileu Galilei (1999). O ensaiador. São Paulo: Nova Cultural.

Harvey, W. (2009). Estudo anatômico do movimento do coração e do sangue nos animais. São Paulo: Unifesp.

La Méttrie, J. (1796). Traité de l'ame. Ouvres philosophiques de La Méttrie. Paris: Charles Tutot impremeur.

Luijpen, W. (1973). Introdução à fenomenologia existencial.. São Paulo: EDUSP.

Merleau-Ponty, M. (1969). Filosofia y lenguaje. $1^{\text {a }}$ edição. Buenos Aires: Proteo.

Ortega y Gasset, J. (1963). Meditação sobre a técnica. Rio de Janeiro: Ibero-Americano.

Porter, R. (2004). Das tripas coração: uma breve história da medicina. $1^{\text {a }}$ Edição. Rio de Janeiro: Record.

Russo, J. (2006). Do corpo-objeto ao corpo pessoa: desnaturalização de um pressuposto médico. In: Souza A., Pitanguy, J. (orgs.). Saúde, corpo e sociedade (pp. 183-194). Rio de Janeiro: Ed. da UFRJ.

Russo, M. (2006). Irritabilidade e sensibilidade halleriana: as origens da fisiologia experimental. In: Russo, M., Caponi, S. (orgs.). Estudos de filosofia e história das ciências biomédicas (pp. 89-101). São Paulo: Discurso Editorial. Sartre, J. P. (1997). O ser e o nada. Petrópolis: Vozes. 